\title{
Surgery for left ventricular aneurysm: Early and late survival after simple linear repair and endoventricular patch plasty
}

\author{
Runar Lundblad, MD \\ Michel Abdelnoor, $\mathrm{PhD}^{\mathrm{b}}$ \\ Jan Ludvig Svennevig, MD
}

From the Department of Thoracic and Car-
diovascular Surgery, ${ }^{\text {a }}$ Rikshospitalet, Oslo,
Norway, and the Research Forum, ${ }^{\text {b Clinical }}$
Epidemiology Unit, Ullevaal University
Hospital, Oslo, Norway.

Received for publication Oct 28, 2003; revisions requested April 7, 2004; accepted for publication April 23, 2004.

Address for reprints: Runar Lundblad, MD, Rikshospitalet, N-0027 Oslo, Norway (Email: runar.lundblad@rikshospitalet.no).

J Thorac Cardiovasc Surg 2004;128:449-56 $0022-5223 / \$ 30.00$

Copyright (C) 2004 by The American Association for Thoracic Surgery

doi:10.1016/j.jtcvs.2004.04.017
Objective: Simple linear resection and endoventricular patch plasty are alternative techniques to repair postinfarction left ventricular aneurysm. The aim of the study was to compare these 2 methods with regard to early mortality and long-term survival.

Methods: We retrospectively reviewed 159 patients undergoing operations between 1989 and 2003. The epidemiologic design was of an exposed (simple linear repair, $\mathrm{n}=74$ ) versus nonexposed (endoventricular patch plasty, $\mathrm{n}=85$ ) cohort with 2 endpoints: early mortality and long-term survival. The crude effect of aneurysm repair technique versus endpoint was estimated by odds ratio, rate ratio, or relative risk and their $95 \%$ confidence intervals. Stratification analysis by using the MantelHaenszel method was done to quantify confounders and pinpoint effect modifiers. Adjustment for multiconfounders was performed by using logistic regression and Cox regression analysis. Survival curves were analyzed with the Breslow test and the log-rank test.

Results: Early mortality was $8.2 \%$ for all patients, $13.5 \%$ after linear repair and $3.5 \%$ after endoventricular patch plasty. When adjusted for multiconfounders, the risk of early mortality was significantly higher after simple linear repair than after endoventricular patch plasty (odds ratio, 4.4; 95\% confidence interval, 1.1-17.8). Mean follow-up was $5.8 \pm 3.8$ years (range, 0-14.0 years). Overall 5-year cumulative survival was $78 \%, 70.1 \%$ after linear repair and $91.4 \%$ after endoventricular patch plasty. The risk of total mortality was significantly higher after linear repair than after endoventricular patch plasty when controlled for multiconfounders (relative risk, 4.5; 95\% confidence interval, 2.0-9.7). Linear repair dominated early in the series and patch plasty dominated later, giving a possible learning-curve bias in favor of patch plasty that could not be adjusted for in the regression analysis.

Conclusions: Postinfarction left ventricular aneurysm can be repaired with satisfactory early and late results. Surgical risk was lower and long-term survival was higher after endoventricular patch plasty than simple linear repair. Differences in outcome should be interpreted with care because of the retrospective study design and the chronology of the 2 repair methods.

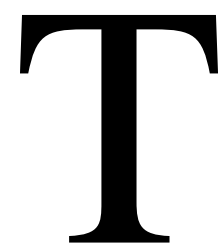

he incidence of coronary artery disease and acute myocardial infarction (MI) is decreasing, and the prognosis is improved by the increased use of thrombolysis or acute percutaneous coronary intervention. Nevertheless, postinfarction left ventricular aneurysm remains a serious disorder that can lead to congestive heart failure $(\mathrm{CHF})$, lethal ventricular arrhythmia, and premature death. According to the law of LaPlace, wall tension will increase with increasing diameter, intracavitary pressure, and wall thinning of the left ventricle (LV). A large and 
TABLE 1. Preoperative characteristics

\begin{tabular}{lccc}
\hline Variable & $\begin{array}{c}\text { Linear repair } \\
(\mathbf{n}=\mathbf{7 4})\end{array}$ & $\begin{array}{c}\text { EVPP } \\
(\mathbf{n}=\mathbf{8 5})\end{array}$ & $\begin{array}{c}\boldsymbol{P} \\
\text { value* }\end{array}$ \\
\hline Age (y) & $61 \pm 9(33-79)$ & $62 \pm 11(42-80)$ & .56 \\
Male/female sex & $60 / 14$ & $63 / 22$ & .29 \\
Stroke & 4 & 5 & 1.0 \\
Diabetes mellitus & 5 & 9 & .40 \\
Uremia & 1 & 0 & .47 \\
Pulmonary disease & 5 & 7 & .73 \\
Previous cardiac surgery & 1 & 1 & 1.0 \\
No. of months from last MI & $44 \pm 54(1-195)$ & $40 \pm 61(1-325)$ & .68 \\
No. of previous Mls & $1.5 \pm 0.9(1-5)$ & $1.4 \pm 0.8(1-5)$ & .41 \\
NYHA class & & & \\
$\quad$ 1-2 & 16 & 19 & .91 \\
$3-4$ & 58 & 66 & \\
Ventricular arrhythmia & 28 & 20 & .05 \\
LVEF (\%) $\dagger$ & $34 \pm 12(10-65)$ & $35 \pm 12(11-62)$ & .59 \\
LVEDP (mm Hg) $\ddagger$ & $21 \pm 8(4-40)$ & $20 \pm 8(8-55)$ & .61 \\
Moderate or severe MR & 5 & 8 & .54 \\
Three-vessel disease & 33 & 35 & .66 \\
LAD lesion & 70 & 81 & 1.0 \\
Left main stenosis & 9 & 7 & .41 \\
Anterior-posterior aneurysm & $70 / 4$ & $80 / 5$ & 1.0 \\
& &
\end{tabular}

Values are presented as means $\pm S D$ (range) or number of patients. EVPP, Endoventricular patch plasty; MI, myocardial infarction; NYHA, New York Heart Association (angina or dyspnea); $L V E F$, left ventricular ejection fraction; $L V E D P$, left ventricular end-diastolic pressure; $M R$, mitral regurgitation; $L A D$, left anterior descending artery.

*Two-tailed Fisher exact test or $\chi^{2}$ test for discrete numeric data or categoric data and 2-tailed $t$ test or Mann-Whitney test for continuous numeric data.

tLeft ventricular ejection fraction was calculated in 137 of 159 cases (linear repair, 57; endoventricular patch plasty, 80).

ҒLeft ventricular end-diastolic pressure was measured in 144 of 159 cases (linear repair, 64; endoventricular patch plasty, 80).

thin-walled aneurysm is subjected to high wall tension, poor coronary perfusion, and further dilation. The ultimate stage of left ventricular aneurysm is enlargement, not only of the aneurysm but also of the global LV. Because the impaired LV cannot generate high blood pressure, this will limit the increase in wall tension and protect against further dilation of the aneurysm and eventually free rupture, which is extremely rare.

Surgical treatment is indicated in established cases of $\mathrm{CHF}$, angina pectoris, malignant ventricular arrhythmia, or recurrent embolization from the LV. The goal of surgical intervention is to correct the size and geometry of the LV, reduce wall tension and paradoxical movement, and improve systolic function. Intracavitary thrombi are removed, and coronary artery bypass grafting (CABG) is usually performed. Aneurysmectomy and linear repair of the LV was introduced by Cooley and colleagues in $1958^{1}$ and remained the standard procedure until the late 1980s. Endoventricular patch plasty (EVPP) was then introduced as a more physiologic repair than the linear closure technique, ${ }^{2,3}$ especially when the aneurysm extends into the septum.
However, there is still controversy whether EVPP is superior to simple linear resection on early and late clinical outcome. Mickleborough and associates ${ }^{4,5}$ have introduced a method combining septoplasty and linear resection. Simple linear closure reduces only the aneurysm of the free wall, while their newer technique targets also the septal part of the aneurysm. In the present retrospective study on patients with postinfarction left ventricular aneurysm, we compare simple linear repair and EVPP with respect to surgical risk and long-term survival.

\section{Materials and Methods \\ Baseline Patient Characteristics}

Between January 1989 and January 2003, 159 patients underwent operations for nonruptured postinfarction left ventricular aneurysm. The cases were reviewed retrospectively in June 2003. The diagnosis and criteria for aneurysmectomy were based on a dyskinetic aneurysm with systolic paradoxical movement. Linear repair $(n=74)$ of the LV was performed mostly in the early part of the period, and $\operatorname{EVPP}(n=85)$ was performed mostly in the later part. There was no statistically significant difference between the groups in baseline patient characteristics except for a borderline variance in the occurrence of clinical manifest ventricular arrhythmia $(P=.05$, Table 1$)$. There were 123 men and 36 women with a mean age of $61.8 \pm 9.5$ years enrolled in the study. Ninety percent of the patients had sustained 1 or 2 MIs preoperatively, and $10 \%$ had experienced multiple MIs. The mean interval between the last MI and aneurysmectomy was 42 months (range, 1-325 months). All patients had symptoms from their left ventricular aneurysms, and 78\% were in New York Heart Association functional class 3 or 4 . Angina, CHF, or a combination of both symptoms led to a surgical procedure in two thirds of the cases. Ventricular arrhythmia, alone or in combination with other symptoms, was the indication in one third of the cases. No patients had implantable cardioverter defibrillators (ICDs) preoperatively. No patients in our series had experienced embolic episodes from the aneurysm.

The left ventricular aneurysm diagnosis relied on echocardiography and cardiac catheterization with left ventriculography and selective coronary angiography. From left ventriculography, left ventricular ejection fraction (LVEF) was calculated in 137 patients, and left ventricular end-diastolic pressure was measured in 144 patients. Left ventricular function was significantly reduced, with LVEF of $34 \% \pm 12 \%$ and left ventricular end-diastolic pressure of $21 \pm 8 \mathrm{~mm} \mathrm{Hg}$. All patients had significant coronary lesions identified on the angiograms. Three-vessel disease was present in $43 \%$, left main stenosis in $10 \%$, and significant left anterior descending artery (LAD) lesion in $95 \%$. The extent of coronary artery pathology and the distribution of 1-, 2-, and 3 -vessel disease did not differ significantly between groups $(P=$ .14). Anterior location of the aneurysm was seen in $150(94 \%)$ patients, and nonanterior location was seen in 9 patients (inferoposterior wall, 5 patients; posterolateral wall, 4 patients).

\section{Operative Technique}

All procedures were performed with cardiopulmonary bypass (CPB) and moderate systemic hypothermia. In 153 of the 159 
patients, the aorta was crossclamped, and cold crystalloid cardioplegic solution was infused through the aortic root as an initial bolus of $1000 \mathrm{~mL}$, followed by 200 to $300 \mathrm{~mL}$ every 20 to 30 minutes. The operative sequence was as follows: the aneurysm was incised parallel to the interventricular septum, the intracavitary thrombus was removed, a ventricular vent was inserted, distal coronary anastomoses were performed, the aneurysm was repaired, the aortic crossclamp was removed, and, finally, proximal anastomoses were performed with the aorta partial excluded. The heart was cardioplegic during the whole procedure, except the proximal anastomosing in 67 of the 153 patients. In the remaining 86 patients, the crossclamp was removed after completion of the distal anastomoses, and therefore the aneurysm repair was performed partly or completely on beating heart. In 6 cases in which CABG was not performed, the aorta was not crossclamped, and the aneurysm repair was performed on a beating heart. For linear repair, the edges were readapted with 2 strips of felt or pericardium for reinforcement by using a combination of continuous sutures and interrupted mattress stitches. For EVPP, a patch of dacron (n $=76)$ or polytetrafluoroethylene $(n=9)$ was attached to the border zone between normal and scarred tissue eventually after a circular purse-string suture was passed to restore a new apical neck $(\mathrm{n}=9)$. The patch was secured with continuous $(\mathrm{n}=39)$ or interrupted mattress $(n=8)$ sutures or a combination of both techniques $(n=38)$. The aneurysmal sac was closed over the patch with 2 strips of felt or pericardium for reinforcement by using a combination of continuous sutures and interrupted mattress stitches. When performed, cryoablation was based on mapping or just visually directed.

During the 14-year period covered by the study, there was a substantial turnover of surgeons. Altogether, there were 18 surgeons involved in 159 operations, resulting in relatively little personal experience (median, 8 procedures). Five surgeons performed less than 5 procedures, and 9 surgeons performed 5 to 10 procedures. Four surgeons did more than 10 procedures, and 1 surgeon performed 47 repairs (linear repair, 26; EVPP, 21). Six surgeons participated only in the linear repair experience, 8 surgeons performed only EVPP, and 4 surgeons performed both procedures.

\section{Statistical Analysis and Epidemiologic Methods}

Continuous numeric data are presented as means \pm SD (range), and discrete numeric data and categoric data are presented as frequencies. Endpoints were early mortality ( $<30$ days) and longterm survival. Univariate analysis was performed by using contingency tables with $\chi^{2}$ or 2-tailed Fisher exact tests for discrete numeric data or categoric data, and the 2-tailed $t$ test or the Mann-Whitney test were used for continuous numeric data. Total mortality was analyzed according to the Kaplan-Meier method, and differences between survival curves were estimated by using the Breslow test and the log-rank test. ${ }^{6}$

The epidemiologic design was of an exposed (linear repair, $\mathrm{n}=$ 74) versus nonexposed (EVPP, $n=85$ ) cohort with the 2 endpoints of early mortality and long-term survival. First, we estimated the crude association between the aneurysmal repair technique and the endpoints. Then a comprehensive search for confounders and effect modifiers was performed by using stratification analysis with the Mantel-Haenszel method. ${ }^{7}$ The Breslow-
TABLE 2. Operative characteristics and postoperative morbidity

\begin{tabular}{lccc}
\hline Variable & $\begin{array}{c}\text { Linear repair } \\
(\mathbf{n}=\mathbf{7 4})\end{array}$ & $\begin{array}{c}\text { EVPP } \\
(\mathbf{n}=\mathbf{8 5})\end{array}$ & $\begin{array}{c}\boldsymbol{P} \\
\text { value* }\end{array}$ \\
\hline Time of operation & & & \\
$\quad$ First half of period & 68 & 12 & .0001 \\
$\quad$ Second half of period & 6 & 73 & \\
Aortic crossclamp time (min) & $25 \pm 20$ & $43 \pm 30$ & .0001 \\
CPB time (min) & $91 \pm 47$ & $114 \pm 127$ & .02 \\
Aneurysm repair on beating & 57 & 35 & .0001 \\
$\quad$ heart & 57 & & \\
CABG & $27 / 70$ & $58 / 81$ & .0001 \\
Graft to diseased LAD & $2.2 \pm 1.0(1-6)$ & $2.3 \pm 1.0(1-5)$ & .56 \\
No. of distal anastomoses & $16 / 28$ & $7 / 20$ & .13 \\
Cryoablation (performed/VA) & 11 & 5 & .06 \\
Reoperation for bleeding & 4 & 2 & .42 \\
Myocardial infarction & 21 & 17 & .22 \\
Inotropy $>$ 24 $h$ & 9 & 4 & .09 \\
IABP & 5 & 4 & .73 \\
Organ failure & &
\end{tabular}

Values are presented as means $\pm \mathrm{SD}$ (range) or number of patients. $E V P P$, Endoventricular patch plasty; $C P B$, cardiopulmonary bypass; $C A B G$, coronary artery bypass grafting; $L A D$, left anterior descending artery; $V A$, ventricular arrhythmia; $I A B P$, intra-aortic balloon pump.

*Two-tailed Fisher exact test or $\chi^{2}$ test for discrete numeric data or categoric data and Mann-Whitney test for continuous numeric data.

Day test for heterogeneity of odds ratios (ORs), rate ratios, or relative risks between strata was used to pinpoint eventual effect modifiers. The confounding effect was quantified, comparing the adjusted Mantel-Haenszel ORs, rate ratios, or relative risks with the corresponding crude values:

$$
\text { Confounding effect }(\%)=\frac{\mathrm{OR}_{\mathrm{MH}}-\mathrm{OR}_{\text {Crude }}}{\mathrm{OR}_{\text {Crude }}} \times 100
$$

Logistic regression and Cox regression analyses were performed to adjust for confounders with a more than $5 \%$ numeric confounding effect. ${ }^{8}$ Manual backward elimination of variables was performed on the basis of the following criteria: clinical or pathophysiologic importance, correlation matrix between the variables, and statistical significance.

\section{Results}

Operative and Postoperative Characteristics

Operative and postoperative data are shown in Table 2. CABG was performed in 128 patients, and the number of distal anastomoses was $2.2 \pm 1.0$ (range, 1-6). The LAD was significantly diseased in 151 patients. It was revascularized with the internal thoracic artery (ITA) in 72 patients and with a vein graft in 13 patients, and this was more frequent in the EVPP group than in the linear repair group. EVPP is more complex and time-consuming, and therefore the CPB and crossclamp times were longer, and fewer aneurysm repair procedures were performed on beating hearts. 


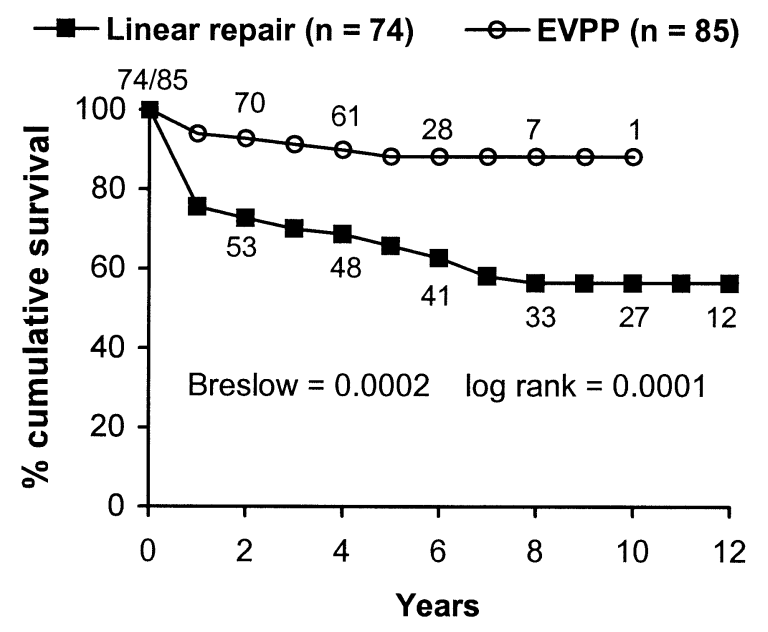

Figure 1. Effect of aneurysm repair technique on cumulative survival. Numbers on curves are patients at risk.

Two patients in the EVPP group, one with aortic stenosis and one with aortic regurgitation, underwent concomitant aortic valve replacement with mechanical valves. Another patient had a previous inferoposterior wall infarction and a large mitral regurgitation and underwent mitral valve replacement and EVPP. Intra-aortic balloon pumping (IABP) was used in $8 \%$, and $24 \%$ needed inotropic agents for more than 24 hours. There was a borderline increase in revision for bleeding and use of IABP in the linear repair group. Five percent experienced noncardiac organ failure, and all these patients had sustained low output syndrome postoperatively. No patients had sternal dehiscence. Forty-eight patients had ventricular arrhythmia in their histories, and cryoablation, eventually combined with endocardial scar resection, was performed in 23 of these patients. Four of these 23 patients have had an ICD implanted later, and 19 have not. Of the 25 patients without cryoablation, 4 have had an ICD implanted later, and 21 have not. No patients had ICDs preoperatively. ICDs were implanted during follow-up in 11 patients altogether; 6 of 85 in the EVPP group and 4 of 74 in the linear repair group $(P=0.58$; OR, 1.4; 95\% confidence interval [CI], 0.4-4.8). ICDs were implanted within 2 months after surgical intervention in 9 patients, after 4 months in 1 patient, and after 7 years in 1 patient. Ventricular arrhythmia appeared preoperatively in 8 of the 11 patients receiving ICDs (cryoablation was performed in 4 of them), and in the remaining 3 patients, ventricular arrhythmia started after the operation.

\section{Early Mortality and Long-term Survival}

Crude effect. Early mortality ( $<30$ days) was $8.2 \%$ (13 patients) for the whole material. Early mortality was $15.4 \%$ in the first 39 patients (95\% linear repair), $7.5 \%$ in the next 40 patients (77.5\% linear repair), $2.5 \%$ in the following 40
TABLE 3. Early and total mortality: Univariate analysis (n $=159$ )

\begin{tabular}{lccccc}
\hline Variable & $\begin{array}{c}\text { Linear repair } \\
(\mathbf{n}=\mathbf{7 4})\end{array}$ & $\begin{array}{c}\text { EVPP } \\
(\mathbf{n}=\mathbf{8 5})\end{array}$ & $\begin{array}{c}\text { OR or } \\
\mathbf{R R}\end{array}$ & $\mathbf{9 5 \%} \mathbf{\text { Cl }}$ & $\boldsymbol{P}$ value* \\
\hline Early mortality & 10 & 3 & $3.8 \dagger$ & $1.1-13.4$ & .02 \\
Total mortality & $31 / 487$ & $9 / 394$ & $2.8 \ddagger$ & $1.3-5.9$ & .005 \\
\hline
\end{tabular}

$E V P P$, Endoventricular patch plasty; $O R$, odds ratio; $R R$, rate ratio; $\mathrm{Cl}$, confidence interval; early mortality, values are numbers of deaths within 30 days; total mortality, values are numbers of deaths divided by numbers of patient-years of follow-up.

${ }^{*} \chi^{2}$ Test.

†Odds ratio.

$\ddagger$ Rate ratio.

patients (7.5\% linear repair), and $7.5 \%$ in the last 40 patients (7.5\% linear repair). Early mortality within each operative group did not change over time. We were not able to detect any effect of surgical experience (number of aneurysm repairs per surgeon) on early mortality. The crude risk of early mortality was significantly higher after linear repair than after EVPP (OR, 3.8; 95\% CI, 1.1-13.4; Table 3).

Mean follow-up was $5.8 \pm 3.8$ years (range, 0-14.0 years), and the total observation time was 881 years. Overall 5 -year cumulative survival was $78 \%$ and was significantly higher in the EVPP group (91.4\%) than in the linear repair group $(70.1 \%$, Figure 1$)$. The crude risk of total mortality was significantly higher after linear repair than after EVPP (relative risk, 2.8; 95\% CI, 1.3-5.9; Table 3). We could not detect any effect of surgical experience (number of aneurysm repairs per surgeon) on long-term survival.

Adjusted effect. The Mantel-Haenszel stratification analysis identified the following significant confounders ( $>5 \%$ numeric confounding effect) for the association between left ventricular aneurysm repair technique and early mortality (Table 4): age greater than 70 years, diabetes mellitus, ventricular arrhythmia in the history, LVEF of $30 \%$ or less, dyspnea in New York Heart Association class 3 or 4 , more than one MI in the history, concomitant CABG, and more than 2 distal anastomoses performed. The following variables were significant confounders for the association between aneurysm repair technique and total mortality: age greater than 70 years, ventricular arrhythmia in the history, more than one MI in the history, and concomitant CABG (Table 5).

When adjusted for multiconfounders, linear repair was associated with higher early mortality (OR, 4.4; 95\% CI, 1.1-17.8) and total mortality (relative risk, $4.5 ; 95 \% \mathrm{CI}$, 2.0-9.7) than EVPP (Table 6). No effect modifiers were identified for the association between aneurysm repair technique and endpoints.

EVPP is a more complex and time-consuming procedure than linear repair, and a cardioplegic heart was often considered to be helpful during patch implantation but not 
TABLE 4. Confounders for early mortality: Mantel-Haenszel stratification analysis $(n=159)$

\begin{tabular}{|c|c|c|c|c|c|c|c|c|}
\hline \multirow[b]{2}{*}{ Variable } & \multicolumn{2}{|c|}{ Early mortality } & \multirow[b]{2}{*}{$\mathbf{O} \mathbf{R}_{\text {ss }}$} & \multirow[b]{2}{*}{$95 \% \mathrm{CI}$} & \multirow[b]{2}{*}{$\mathbf{O R}_{\mathrm{MH}}$} & \multirow[b]{2}{*}{ 95\% CI } & \multirow[b]{2}{*}{$\begin{array}{c}\text { Heterogeneity } \\
\text { test* }^{*}\end{array}$} & \multirow[b]{2}{*}{$\begin{array}{c}\text { Confounding } \\
\text { effect }(\%)\end{array}$} \\
\hline & $\begin{array}{c}\text { LR } \\
(n=74)\end{array}$ & $\begin{array}{c}\text { EVPP } \\
(\mathrm{n}=85)\end{array}$ & & & & & & \\
\hline \multicolumn{9}{|c|}{ Age $>70 y$} \\
\hline Yes & $5 / 14$ & $2 / 23$ & 5.8 & $0.9-36$ & 5.7 & $1.4-23$ & 0.97 & 33 \\
\hline No & $5 / 60$ & $1 / 62$ & 5.6 & $0.6-49$ & & & & \\
\hline \multicolumn{9}{|l|}{ Diabetes } \\
\hline Yes & $1 / 5$ & $1 / 9$ & 2.0 & $0.1-41$ & 4.6 & $1.2-18$ & 0.55 & 9 \\
\hline No & $9 / 69$ & $2 / 76$ & 5.5 & $1.2-27$ & & & & \\
\hline \multicolumn{9}{|c|}{ Ventricular arrhythmia } \\
\hline Yes & $7 / 28$ & $1 / 20$ & 6.3 & $0.7-56$ & 3.7 & $0.9-14$ & 0.46 & -14 \\
\hline No & $3 / 46$ & $2 / 65$ & 2.2 & $0.4-14$ & & & & \\
\hline \multicolumn{9}{|c|}{ LVEF $\leq 30 \%$} \\
\hline Yes & $5 / 27$ & $2 / 27$ & 2.8 & $0.5-16$ & 3.7 & $0.9-15$ & 0.63 & -12 \\
\hline No & $3 / 30$ & $1 / 53$ & 5.8 & $0.6-58$ & & & & \\
\hline \multicolumn{9}{|l|}{ Dyspnea } \\
\hline \multicolumn{9}{|c|}{ NYHA class 3-4 } \\
\hline Yes & $4 / 38$ & $1 / 51$ & 5.9 & $0.6-55$ & 4.0 & $1.1-15$ & 0.67 & -6 \\
\hline No & $6 / 36$ & $2 / 34$ & 3.2 & $0.6-17$ & & & & \\
\hline \multicolumn{9}{|c|}{ No. of Mls $>1$} \\
\hline Yes & $7 / 25$ & $1 / 23$ & 8.6 & $1.0-76$ & 4.0 & $1.1-15$ & 0.30 & -6 \\
\hline No & $3 / 49$ & $2 / 62$ & 2.0 & $0.3-12$ & & & & \\
\hline \multicolumn{9}{|c|}{ CABG performed } \\
\hline Yes & $9 / 57$ & $3 / 71$ & 4.3 & 1.1-1.7 & 4.7 & $1.2-18$ & 0.65 & 9 \\
\hline No & $1 / 17$ & $0 / 14$ & & & & & & \\
\hline \multicolumn{9}{|c|}{ No. of distal anastomoses $>2$} \\
\hline Yes & $6 / 57$ & $1 / 58$ & 6.7 & $0.8-58$ & 5.1 & $1.3-20$ & 0.70 & 19 \\
\hline No & $4 / 17$ & $2 / 27$ & 3.8 & $0.6-24$ & & & & \\
\hline
\end{tabular}

Fractions are numbers of early deaths divided by numbers of patients at risk. Crude odds ratio for linear repair versus endoventricular patch plasty on endpoint early mortality was 4.3 (95\% confidence interval, 1.1-16.2) when all 159 patients were included. Left ventricular ejection fraction was calculated in 137 of 159 cases, with a crude odds ratio of 4.2 (95\% confidence interval, 1.1-16.6).

$L R$, Linear repair; $E V P P$, endoventricular patch plasty; $O R_{S S}$, stratum-specific odds ratio; $C l$, confidence interval of $O \mathrm{R}$; $O R_{M H}$, Mantel-Haenszel adjusted odds ratio; $L V E F$, left ventricular ejection fraction; NYHA, New York Heart Association; MI, myocardial infarction; CABG, coronary artery bypass grafting. ${ }^{*}$ Breslow-Day test for heterogeneity of odds ratios between strata.

TABLE 5. Confounders for total mortality: Mantel-Haenszel stratification analysis $(n=159)$

\begin{tabular}{|c|c|c|c|c|c|c|c|c|}
\hline Variable & $\begin{array}{c}\text { LR } \\
(n=74)\end{array}$ & $\begin{array}{c}\text { EVPP } \\
(n=85)\end{array}$ & $\mathbf{R R}_{\text {ss }}$ & $\mathrm{Cl}_{\text {ss }}$ & $\mathbf{R R}_{\mathrm{MH}}$ & $\mathrm{Cl}_{\mathrm{MH}}$ & $\begin{array}{c}\text { Heterogeneity } \\
\text { test* }^{*}\end{array}$ & $\begin{array}{c}\text { Confounding } \\
\text { effect }(\%)\end{array}$ \\
\hline \multicolumn{9}{|c|}{ Age $>70 y$} \\
\hline Yes & $8 / 51$ & $4 / 76$ & 5.8 & $0.9-36$ & 5.7 & $1.4-23$ & 0.97 & 33 \\
\hline No & $23 / 435$ & $1 / 62$ & 5.6 & $0.6-49$ & & & & \\
\hline \multicolumn{9}{|c|}{ Ventricular arrhythmia } \\
\hline Yes & $14 / 152$ & $4 / 84$ & 1.9 & $0.6-5.9$ & 2.5 & $1.2-5.3$ & 0.52 & -9 \\
\hline No & $3 / 46$ & $2 / 65$ & 2.2 & $0.4-14$ & & & & \\
\hline \multicolumn{9}{|c|}{ No. of Mls $>1$} \\
\hline Yes & $17 / 107$ & $3 / 114$ & 6.0 & $1.8-20$ & 3.0 & $1.5-6.2$ & 0.11 & 8 \\
\hline No & $14 / 380$ & $6 / 280$ & 1.7 & $0.7-4.5$ & & & & \\
\hline \multicolumn{9}{|c|}{ CABG performed } \\
\hline Yes & $27 / 328$ & $8 / 306$ & 3.2 & $1.4-6.9$ & 3.0 & $1.5-6.4$ & 0.77 & 8 \\
\hline No & $4 / 158$ & $1 / 88$ & 2.2 & $0.3-20$ & & & & \\
\hline
\end{tabular}

Fractions are numbers of deaths divided by numbers of patient-years of follow-up. Crude rate ratio for linear repair versus EVPP on end point total mortality was $2.8(95 \%$ confidence interval, 1.3-5.9) when all 159 patients were included.

$L R$, Linear repair; $E V P P$, endoventricular patch plasty; $R R_{S S}$, stratum-specific rate ratio; $C l_{S S^{\prime}}$ confidence interval of stratum-specific rate ratio; $R R_{M H}$ Mantel-Haenszel adjusted rate ratio; $C I_{M{ }^{\prime}}$ confidence interval of Mantel-Haenszel adjusted rate ratio; $M I$, myocardial infarction; $C A B G$, coronary artery bypass grafting.

*Breslow-Day test for heterogeneity of rate ratios between strata. 
TABLE 6. Linear repair versus endoventricular patch plasty: Adjusted effect on early and total mortality $(\mathrm{n}=159)$

\begin{tabular}{lcccccr}
\hline Early mortality & & & & & & \\
\hline Variable & Level & $\boldsymbol{\beta}$ & SE of $\boldsymbol{\beta}$ & OR & Cl & $\boldsymbol{P}_{\text {value* }}^{*}$ \\
\hline Linear repair & Yes/no & 1.5 & 0.7 & 4.4 & $1.1-17.8$ & .04 \\
\hline Total mortality & & & & & & \\
\hline Variable & Level & $\boldsymbol{\beta}$ & SE of $\boldsymbol{\beta}$ & RR & Cl & $\boldsymbol{P}$ valuet \\
\hline Linear repair & Yes/no & 1.5 & 0.4 & 4.5 & $2.0-9.7$ & .0001 \\
\hline
\end{tabular}

One hundred fifty-nine cases of left ventricular aneurysm were operated on with linear repair $(\mathrm{n}=74)$ or endoventricular patch plasty $(\mathrm{n}=85)$.

$\beta$, Regression coefficient; $\mathrm{Cl}$, confidence interval of odds ratio or relative risk; $O R$, odds ratio; $R R$, relative risk.

*Logistic regression with manual backward elimination. Variables adjusted for in the model included age, diabetes mellitus, ventricular arrhythmia in the history, left ventricular ejection fraction, New York Heart Association class (dyspnea), number of myocardial infarctions in the history, concomitant coronary artery bypass grafting, and number of distal anastomoses.

tCox regression with manual backward elimination. Variables adjusted for in the model included age, ventricular arrhythmia in the history, number of myocardial infarctions in the history, and concomitant coronary artery bypass grafting.

essential in simple linear resection. Accordingly, CPB and aortic crossclamp times were significantly longer in the EVPP group. These 2 variables were not adjusted for in the regression analyses because they are only surrogates for the repair technique. Linear resection dominated early in the series and EVPP dominated later, but with some overlapping. The effect of learning curve of the institutional team could therefore represent a potential bias in favor of EVPP. However, the date of the operation could not be adjusted for in the regression analysis because it was highly associated with exposure (repair technique), being a surrogate for the same phenomenon.

\section{Discussion}

In this study surgical risk was lower and long-term survival was higher after EVPP than after simple linear repair of postinfarction left ventricular aneurysm. No controlled studies have been performed to evaluate long-term survival after surgical and modern medical treatment or to compare outcome after EVPP and linear repair. There is still controversy as to whether EVPP is superior to simple linear repair on early and late clinical outcome. Although the present study demonstrated better long-term survival after EVPP, other retrospective reports fail to demonstrate any difference in survival between the 2 methods. ${ }^{9-15}$ However, these studies include relatively small numbers of patients and cover a long period of time, making interpretation of data and possible residual bias difficult. Eventual superior results after EVPP might be explained by improved conditions for concomitant revascularization of the LAD and a more physiologic shape of the LV compared with those after traditional simple linear repair.

\section{Aneurysm Repair and Ventricular Arrhythmia}

Ventricular arrhythmia in the history indicates reduced long-term survival. ${ }^{10,15}$ Ventricular arrhythmia was present in 48 of the 159 patients and represented a significant risk factor for early and total mortality independent of surgical repair method (not shown). Ventricular arrhythmia arises in the border zone between viable and dead myocardium, usually on the interventricular septum. Simple linear resection with or without concomitant CABG often fails to control ventricular arrhythmia. EVPP and linear resection combined with septoplasty might reduce wall tension on the septal border zone, and it is hypothesized that this might have an inherent antiarrhythmic effect. ${ }^{16}$ However, this is not supported in other clinical studies, and no experimental data exist.

\section{Aneurysm Repair and CABG}

Concomitant $\mathrm{CABG}$ is highly recommended for 2 reasons. First, it reduces or prevents angina pectoris. Second, although the LAD is occluded and the periphery on the free wall is thin or calcified, an ITA graft to the LAD might be particularly important to improve septal perfusion and control ventricular arrhythmia. In the present study revascularization of the LAD was significantly more frequent in the EVPP group (72\%) than in the linear repair group (39\%). The importance of an ITA graft to the LAD during complex operations was probably underestimated in the first period of the series, when linear repair dominated. Moreover, with this technique, the aneurysmal sac is partly removed, and the remnant is used for closure of the LV, which could render revascularization of the LAD more difficult. During EVPP, more of the aneurysmal sac is retained, and therefore the conditions for revascularization of the LAD might be better. CABG was performed in 128 of the 159 patients, and the LAD was revascularized in 78 of the 151 patients with LAD lesions. The number of distal anastomoses did not differ between groups and had no effect on early mortality $(P=.30)$ and long-term survival $(P=.59)$. Incomplete revascularization had different reasons: thin or calcified 
coronary peripheries, poor venuous or arterial conduits, or an LAD running into the aneurysmal sac to be removed. Lack of revascularization of the LAD had no statistically significant adverse effect on early mortality $(P=.44)$ or long-term survival $(P=.30)$. CABG is generally recognized as an important part of left ventricular aneurysm operations, irrespective of repair technique. Improved results might have been achieved with a more aggressive approach on revascularization, especially of the LAD.

\section{Aneurysm Repair and Left Ventricular Function}

Low LVEF is a predictor for reduced long-term survival after left ventricular aneurysm repair. ${ }^{10,13,15,17,18}$ Unless it is extremely low, a reduced LVEF per se should not contradict an operation because historical data show a poor lifespan without surgical intervention in symptomatic patients. ${ }^{19}$ Only global LVEF was calculated in this study. This represents both the contractile and the noncontractile aneurysmal parts of the LV. Because noncontractile tissue is removed during aneurysm repair, the state of the contractile portion of the LV is probably a better predictor for cardiac performance after surgical intervention.

EVPP was introduced as a more physiologic repair than the traditional simple linear resection technique. EVPP is supposed to provide a more physiologic apex, whereas the distal end of the LV is more flattened after simple linear repair. EVPP can improve left ventricular function ${ }^{17,20,21}$ and is probably more effective than traditional simple linear resection. ${ }^{9,16}$ Both methods clearly improve functional status. ${ }^{4,9,10,12,14-16,20}$ Some studies report superior functional improvement after EVPP than after simple linear repair, ${ }^{12,14-16}$ whereas others fail to demonstrate any functional difference between the 2 methods. ${ }^{9,10,13}$ The present study compares EVPP with the traditional simple linear resection. The more sophisticated technique of Mickleborough and associates, ${ }^{4,5}$ using septoplasty and linear repair, might provide equally good results as EVPP. They report improvement in left ventricular function associated with good symptomatic relief and long-term survival. In small aneurysms not involving the septum, the theoretic advantages of EVPP are less convincing.

\section{Limitations of the Study}

Left ventricular aneurysm can be defined as an area of asynergy (either akinetic or dyskinetic) that is large enough to reduce left ventricular function. This is a very loose definition, and the lack of uniformity of aneurysm criteria complicates almost all discussions of left ventricular aneurysm repair. In the present report the diagnosis and criteria for aneurysmectomy were based on a dyskinetic aneurysm with systolic paradoxical movement. However, there is a continuum between akinesia and dyskinesia, and there are obvious border zones between these entities. Aneurysmec- tomy was originally introduced for dyskinetic aneurysms, and controversy has existed as to whether patients with akinetic aneurysms would benefit from surgical intervention. Recent reports suggest that both left ventricular dysfunction and the outcome of surgical intervention depend on the extent of asynergy rather than the type of asynergy (akinetic or dyskinetic). ${ }^{4,17,22,23}$ Wall thinning of the asynergic area was not systematically quantified in our study, either preoperatively or perioperatively.

We have performed an observational study with 2 cohorts exposed to different surgical methods and operated on at different time points. This is not the ideal design to evaluate the efficacy of a new surgical technique because of selection bias, residual confounding bias, and eventually some unknown confounders for which it is impossible to control. The ideal design is the randomized clinical trial. However, the promising results after EVPP, combined with the relatively small number of patients in each center, makes a randomized study difficult to carry out.

Our study covered a period of 14 years, and although we tried to control for multiconfounder bias by means of stratification analysis and multivariate methods, there could be hidden mechanisms of selection between the 2 surgical groups for which we did not manage to adjust. There was a continuous turnover of surgeons throughout the study, with 18 involved altogether. Only one surgeon gained significant experience (47 cases), whereas the other surgeons performed few procedures (median, 8), and therefore a benefit from surgical training with aneurysmectomy could not be demonstrated in the statistical analysis. Nevertheless, the general experience in cardiac surgery has improved over time. Linear resection dominated early in the series and EVPP dominated later, but with some overlapping. The effect of a learning curve on the institutional team could therefore represent a potential bias in favor of EVPP. However, this could not be corrected for in the regression analysis because of the problem of overadjustment. One cannot adjust for a variable (date of the operation) that is highly associated with exposure (repair technique) because it is a surrogate for the same phenomenon. Adjustment in this case will create difficulties in the analysis, and the results could be difficult to interpret. ${ }^{7}$ The lower incidence of reoperation for bleeding and use of an IABP late in the series could support a bias of learning curve favoring EVPP. On the other hand, for each particular surgical method, these 2 incidents did not change over time. Alternative explanations are that EVPP might be safer when it comes to bleeding because the LV is closed in 2 layers (patch and ventricular wall), and a more physiologic shape of the LV after EVPP might lead to reduced need for IABP. Altogether, differences in outcome should be interpreted with care because of the retrospective study design and because of the chronology of the 2 procedures, resulting in a possible learning- 
curve bias in favor of EVPP that could not be adjusted for in the regression analysis.

\section{Conclusions}

Postinfarction left ventricular aneurysm can be repaired with satisfactory early and late clinical outcomes. In the present study surgical risk was lower and long-term survival was higher after EVPP than after simple linear repair. The difference in outcome should be interpreted with care because of the retrospective study design and because of the chronology of the 2 methods, resulting in a possible learning-curve bias in favor of EVPP.

\section{References}

1. Cooley DA, Collins HA, Morris GC, Chapman DW. Ventricular aneurysm after myocardial infarction: surgical excision with use of temporary cardiopulmonary bypass. JAMA. 1958;167:557-60.

2. Dor V, Saab M, Coste P, Kornaszewska M, Montiglio F. Left ventricular aneurysm: a new surgical approach. Thorac Cardiovasc Surg. 1989;37:11-9.

3. Cooley DA. Ventricular endoaneurysmorrhaphy: a simplified repair for extensive postinfarction aneurysm. J Card Surg. 1989;4:200-5.

4. Mickleborough LL, Carson S, Ivanov J. Repair of dyskinetic or akinetic left ventricular aneurysm: results obtained with a modified linear closure. J Thorac Cardiovasc Surg. 2001;121:675-82.

5. Mickleborough LL, Maruyama H, Liu P, Mohamed S. Results of left ventricular aneurysmectomy with a tailored scar excision and primary closure technique. J Thorac Cardiovasc Surg. 1994;107:690-8.

6. Altman DG. Practical statistics for medical research. London: Chapman \& Hall; 1991. p. 365-95.

7. Kleinbaum DG, Sullivan KM, Barker ND. ActivEpi companion textbook. New York: Springer-Verlag; 2003.

8. Kleinbaum DG, Kupper LL, Muller KE, Nizham A. Applied regression analysis and other multivariate methods. 3rd ed. Pacific Grove (CA): Duxburry Press; 1998.

9. Doss M, Martens S, Sayour S, Hemmer W. Long term follow up of left ventricular function after repair of left ventricular aneurysm. A comparison of linear closure versus patch plasty. Eur J Cardiothorac Surg. 2001;20:783-5.

10. Komeda M, David TE, Malik A, Ivanov J, Sun Z. Operative risks and long-term results of operation for left ventricular aneurysm. Ann Thorac Surg. 1992;53:22-8.

11. Pasini S, Gagliardotto P, Punta G, et al. Early and late results after surgical therapy of postinfarction left ventricular aneurysm. J Cardiovasc Surg. 1998;39:209-15.

12. Shapira OM, Davidoff R, Hilkert RJ, Aldea GS, Fitzgerald CA, Shemin RJ. Repair of left ventricular aneurysm: long-term results of linear repair versus endoaneurysmorrhaphy. Ann Thorac Surg. 1997; 63:701-5.

13. Tavakoli R, Bettex D, Weber A, et al. Repair of postinfarction dyskinetic LV aneurysm with either linear or patch technique. Eur J Cardiothorac Surg. 2002;22:129-34.

14. Vicol C, Rupp G, Fischer S, Summer C, Dietrich BH, Struck E. Linear repair versus ventricular reconstruction for treatment of left ventricular aneurysm: a 10-year experience. J Cardiovasc Surg. 1998;39:461-7.

15. Vural KM, Şener E, Özatik MA, Taşdemir O, Bayazit K. Left ventricular aneurysm repair: an assessment of surgical treatment modalities. Eur J Cardiothorac Surg. 1998;13:49-56.

16. Sinatra R, Macrina F, Braccio M, et al. Left ventricular aneurysmectomy; comparison between two techniques; early and late results. Eur J Cardiothorac Surg. 1997;12:291-7.

17. Menicanti L, Di Donato M. The Dor procedure: what has changed after fifteen years of clinical practice? J Thorac Cardiovasc Surg. 2002; 124:886-90.

18. Vauthey JN, Berry DW, Snyder DW, et al. Left ventricular aneurysm repair with myocardial revascularization: an analysis of 246 consecutive patients over 15 years. Ann Thorac Surg. 1988;46:29-35.

19. Grondin P, Kretz JG, Bical O, Donzeau-Gouge P, Petitclerc R, Campeau L. Natural history of saccular aneurysms of the left ventricle. J Thorac Cardiovasc Surg. 1979;77:57-64.

20. Di Mattia DG, Di Biasi P, Salati M, Mangini A, Fundaro P, Santoli C. Surgical treatment of left ventricular post-infarction aneurysm with endoventriculoplasty: late clinical and functional results. Eur J Cardiothorac Surg. 1999;15:413-8.

21. Kawata T, Kitamura S, Kawachi K, Morita R, Yoshida Y, Hasegawa J. Systolic and diastolic function after patch reconstruction of left ventricular aneurysms. Ann Thorac Surg. 1995;59:403-7.

22. Di Donato M, Sabatier M, Dor V, Toso A, Maioli M, Fantini F. Akinetic versus dyskinetic postinfarction scar: relation to surgical outcome in patients undergoing endoventricular circular patch plasty repair. J Am Coll Cardiol. 1997;29:1569-75.

23. Dor V, Sabatier M, Di Donato M, Montiglio F, Toso A, Maioli M. Efficacy of endoventricular patch plasty in large postinfarction akinetic scar and severe left ventricular dysfunction: comparison with a series of large dyskinetic scars. J Thorac Cardiovasc Surg. 1998;116:50-9. 